\title{
Centralização e padronização dos currículos: posições e tomadas de posição ${ }^{1}$
}

Antônio Augusto Gomes Batista*

Rosário Silvana Genta Lugli**

Vanda Mendes Ribeiro**

*(Centro de Estudos e Pesquisas em Educação, Cultura e Ação Comunitária - Cenpec, São Paulo, SP, Brasil)

**(Universidade Federal de São Paulo

- Unifesp, São Paulo, SP, Brasil)

*** (Universidade Cidade de São Paulo - Unicid, São Paulo, SP, Brasil)
Resumo: Este trabalho, de natureza exploratória, tem por objeto a construção do espaço das tomadas de posição e argumentos sobre o debate a respeito do processo de centralização e padronização curricular no país, por meio de uma Base Nacional Curricular Comum. Tem também por objetivo examinar as relações entre as tomadas de posição e argumentos e a posição social dos indivíduos entrevistados - agentes que participam do debate público sobre o tema, porém atuando em diferentes campos do mundo social. Assim construído, o objeto de pesquisa se insere no quadro da sociologia de inspiração bourdieusiana, de modo central em sua teorização sobre os campos sociais. Para realização da investigação, foram efetuadas entrevistas com 103 nomes que em geral participam do debate educacional (academia, sociedade civil, educação básica, sindicatos, gestão pública), de todas as regiões do país, entrevistados, com base num roteiro semiestruturado, entre o final de 2013 e início de 2014. A análise permitiu que fossem construídas as tomadas de posição, relacionadas a algumas das posições sociais dos indivíduos, especialmente a posição em seu campo e em relação às esferas de decisão política.

Palavras-chave: Currículo. Base Nacional Comum Curricular. Política educacional.

Versão preliminar deste artigo foi apresentada a convite dos GTs de Educação Infantil e Alfabetização, numa Sessão Especial da 37ạ Reunião da Anped, em 2015. 


\section{APRESENTAÇÃO}

Em junho de 2014, o Congresso aprova o Plano Nacional de Educação (PNE). Entre suas estratégias para a consecução de uma educação básica de qualidade e com um fluxo adequado, está o estabelecimento de uma "base nacional comum curricular”, organizada em torno da proposição, "para cada ano" (p. 28) dos níveis fundamental e médio, de "direitos e objetivos de aprendizagem e desenvolvimento para os(as) alunos(as)" (BRASIL, 2014, p. 13).

Antes da aprovação do PNE, a discussão sobre a existência de uma Base Nacional Comum Curricular (doravante BNCC) causou polêmica. A discussão se estende até hoje, após sua aprovação e o lançamento de sua versão final, com diferentes grupos disputando, na esfera do debate educacional, a atribuição de suas finalidades e o estabelecimento de sua natureza.

É no quadro do início dessas disputas - quando elas se organizavam em torno da existência mesma de uma base - que surgiu esta pesquisa. Ela foi demandada por um grupo de advocacy posicionado a favor de uma BNCC, que financiou um conjunto de investigações a fim de reunir elementos para orientar sua ação ${ }^{2}$. Em nosso caso, tratou-se de coletar e analisar argumentos favoráveis e desfavoráveis de agentes envolvidos no debate sobre pertinência da proposição de uma BNCC.

Nosso grupo de pesquisa aceitou a demanda com as seguintes condições: (i) que se tratasse de fato de uma investigação, com um objeto a ser construído, e não de uma pesquisa de opinião, diretamente orientada para a busca de incidência do grupo sobre políticas públicas e por essa busca influenciada; (ii) que os resultados da investigação fossem publicizados e servissem a todos os envolvidos no debate, e não apenas ao grupo que a havia demandado originalmente; (iii) que, de acordo com o código de ética na pesquisa, os

Trata-se de um grupo que reúne agentes com diferentes posicionamentos ideológicos, mas que compartilham o ponto de vista da necessidade da adoção de uma BNCC. Entre seus membros estão deputados federais, ex-dirigentes do MEC, secretários e ex-secretários estaduais e municipais de Educação, ligados a distintos partidos, representantes da Undime e do Consed, fundações familiares e empresariais, membros de conselhos estaduais, municipais e nacional de Educação, bem como organizações não governamentais e, em menor número, professores universitários. Suas posições estão expressas no site "Base Nacional Comum da Educação" (http://basenacionalcomum. org.br). A demanda e o acompanhamento da investigação foram feitos pela Fundação Lemann, que também financiou a pesquisa. 0 aporte financeiro foi também fornecido pelas fundações Telefónica e Roberto Marinho. 
entrevistados não fossem identificados, sendo garantido seu anonimato em todas as etapas da investigação; (iv) que a pesquisa, como qualquer investigação, fosse submetida à avaliação da comunidade científica, para sua discussão e validação.

A pesquisa: objeto e metodologia

A pesquisa teve por objeto a construção do espaço das tomadas de posição (favoráveis, desfavoráveis, argumentos) sobre os processos de padronização e centralização curricular envolvidos na construção de uma BNCC. A pesquisa buscou também relacionar as tomadas de posição com algumas características da posição social dos indivíduos.

Por mais que, em tese, uma base seja elaborada por meio de processos democráticos e compactuados pelos entes da Federação, implica necessariamente uma centralização da política curricular pela União, bem como uma padronização de uma dimensão significativa das diretrizes dos currículos escolares, já que parte delas passa a ser comum.

Assim construído, o objeto de pesquisa se insere no quadro da sociologia de inspiração bourdieusiana, de modo central em sua teorização sobre os campos sociais ${ }^{3}$, compreendidos como espaços relativamente autônomos do campo social mais amplo. Esses espaços são organizados com base num conjunto de relações e posições estruturadas em função de um objeto de disputa, em torno do qual agentes e grupos de agentes disputam entre si o poder de fazer valer, entre outras coisas, a visão legítima desse objeto. Isso tem como pressuposto que os participantes de um campo partilham um conjunto de valores e disposições - um habitus - que permite o reconhecimento do que está em jogo, bem como a disposição para jogá-lo de acordo com um determinado horizonte de possibilidades dado pelo próprio campo (sobre esse horizonte ou "espaço de possíveis", ver BOURDIEU, 1994). Decorre da estrutura dos campos sociais que há posições relativas ao objeto em disputa com valores diferenciais de legitimidade dados pela posse dos capitais próprios a cada campo - acumulados ao longo de uma trajetória. Disso também decorre que o espaço de posições é fortemente hierarquizado e que os agentes que possuem maior legitimidade ou capital de autoridade num campo têm maior chance de fazer-se ouvir, de contar com a crença mágica no valor e na verdade de seu discurso (ver BOURDIEU, 1981).

Em espaços como o educacional, em que há uma forte dependência em Para uma apresentação de conceito de campo, ver BOURDIEU (1983) e BOURDIEU; WACQUANT (1992). 
relação ao campo político e burocrático - vale dizer, das instâncias decisórias centrais, Ministério da Educação (MEC), do Conselho Nacional de Educação (CNE) e do Congresso -, o grau de legitimidade dos agentes, quer dizer, sua capacidade de fazer-se ouvir e de contar com a crença no valor e na verdade de seu discurso, depende especialmente de sua proximidade com o campo de poder político, vale dizer, de seu capital político - de seu poder de tomar decisões políticas e de implementá-las, bem como de influenciar aqueles que tomam essas decisões e as implementam. Depende, ainda, de seu capital acadêmico, ou seja, do conjunto de títulos, honrarias, publicações que, acumulados ao longo de uma trajetória, expressam o reconhecimento do mérito científico dessa trajetória. Ao que tudo indica, é a posse dessas duas formas de capital - seu volume e estrutura -, associada à capacidade de mobilizá-los em presença midiática e ao capital econômico das instituições de que participam os agentes, que permite, no espaço do debate sobre a educação, dizer e ser ouvido, e, sobretudo, de ser ouvido com "boa vontade interpretativa" (ECO, 1986), com disposições favoráveis a adotar os mesmos pontos de vista, em função da crença na legitimidade do agente ou da instituição.

Considerando esses pressupostos, a investigação realizou dois movimentos. Em primeiro lugar, o objetivo foi estabelecer os campos que buscam dizer a verdade sobre o currículo, isto é, que disputam entre si na discussão sobre os processos de centralização e padronização envolvidos na instituição de uma BNCC.

O estabelecimento desses campos em disputa foi realizado pela análise documental, como artigos na imprensa, documentos do CNE, do MEC, dos participantes do próprio grupo que demandou a pesquisa, bem como de entrevistas prévias com ex-dirigentes do Ministério e relatos de envolvidos no próprio debate. Essa análise levou ao estabelecimento de quatro grandes grupos em disputa:

- Organizações da sociedade civil (OSCS), grupo no qual se inseriram também sindicatos docentes, organismos internacionais, organizações voltadas para a defesa de direitos, fundações familiares e empresariais, bem como "consultores" que possuem uma forte presença na mídia e em conselhos de fundações empresariais

- Universidade, predominantemente professores de faculdades de Educação

- Gestão pública (Secretarias de Educação estaduais e municipais, conselhos nacional, estaduais, municipais, órgãos do MEC) 
- Escola (educadores da rede pública e privada - de gestores a professores)

Definidos esses grupos, buscou-se, em segundo lugar, realizar o primeiro movimento que Bourdieu indica como necessário na construção de um campo (BOURDIEU; WACQUANT, 1992, p. 104-105): estabelecer sua relação com o campo do poder. Em nosso caso, buscou-se, com alguma liberdade em relação ao trabalho do sociólogo, apreender a relação de proximidade dos agentes pertencentes aos grupos definidos acima com as instâncias que possuem o poder de decidir sobre o currículo: MEC, CNE, Congresso. Para isso, procurou-se apreender o capital político dos agentes, seja tendo em vista os postos que ocupavam, seja tendo em vista sua participação em comissões, assessorias, seu poder midiático ou econômico, que os habilita a financiar ações do próprio Ministério, como a contratação de especialistas internacionais em currículo, por exemplo. Procurou-se, além disso, determinar o capital de autoridade acadêmica dos agentes, para o que foi necessário reunir informações que evidenciassem seu reconhecimento por acadêmicos, mesmo que esses agentes atuassem no campo da gestão pública, da escola ou da sociedade civil (aliás, os dados mostraram uma forte presença de agentes que, originários do campo acadêmico, "migram” para o campo da gestão ou para o da sociedade civil).

Só então, após esses dois movimentos de análise, buscaram-se apreender os argumentos que os agentes utilizam para justificar suas posições contrárias ou favoráveis, bem como as relações entre suas posições no espaço social e o conjunto dessas tomadas de posição (contrárias ou favoráveis e os argumentos que lhes dão base).

Esses movimentos definiram a metodologia de pesquisa. Selecionaram-se para entrevistas cem nomes pertencentes aos distintos grupos envolvidos no debate, distribuídos em polos regionais para organizar a logística ${ }^{4}$.

O conjunto do grupo acabou por ser constituído por 103 sujeitos, entrevistados durante os meses finais de 2013 e os iniciais de 2014, por uma equipe de pesquisadores contratados ${ }^{5}$. As entrevistas foram, dessa forma, realizadas

Na região Sul (Porto Alegre e Curitiba); Sudeste (São Paulo, Rio de Janeiro e Belo Horizonte); Centro-Oeste (Brasília); Nordeste (Recife e Fortaleza); Norte (Belém e Manaus).

5 Trata-se de uma equipe de uma empresa de pesquisa qualitativa de mercado, contratada com a finalidade de coleta de dados. A análise da condução das entrevistas mostrou, em geral, uma adequada condução. Em muitos casos, porém, percebeu-se uma intimidação dos entrevistadores diante dos entrevistados, que terminaram conduzindo a entrevista, 
antes da aprovação do PNE e da consequente assunção do caráter obrigatório da BNCC. Revelam, portanto, um estado ou momento das relações de força do debate sobre a base, não apenas por causa da aprovação do PNE, mas também porque mudam os agentes, que alteram suas tomadas de posição, seja porque deslocam suas posições no espaço, seja porque modificam seus pontos de vista no próprio debate. Em razão da pouca clareza de um entrevistado, uma entrevista foi anulada. Foram, assim, analisadas 102 entrevistas.

Elas foram realizadas com base num roteiro semiestruturado, que admitia certa flexibilidade. Dada a construção do objeto - voltado sobretudo para processos de centralização de políticas curriculares e de padronização do currículo -, apenas a partir de certa altura o roteiro explorava diretamente a questão da BNCC, por meio de uma definição genérica de base curricular, sobre a qual o entrevistado deveria se posicionar e comentar. Todo restante da entrevista, porém, solicitava que os entrevistados discorressem a respeito de um "currículo nacional" (tomado como uma expressão de "senso comum") e sobre ele se posicionassem, examinando condições para sua concordância, especificações do próprio conceito de “currículo”, bem como seus argumentos. Essa estratégia buscava evitar que os agentes se limitassem a manifestar, desde o início, sua opinião sobre um objeto pré-construído - a BNCC -, para se concentrar nos processos que constituíam objeto da investigação: a centralização das decisões sobre o currículo envolvida pela instituição de uma BNCC, bem como a padronização decorrente dessa instituição.

Neste trabalho, examinam-se sobretudo os dados relativos à parte das entrevistas sobre as tomadas de posição acerca da possibilidade de centralização e padronização curricular em nível nacional, deixando para outra ocasião a análise da parte que abordava diretamente a base. Esta parte - por trazer uma definição de BNCC - levou os entrevistados a manifestarem principalmente suas ressalvas à definição, não permitindo que desenvolvessem seus pontos de vista - mesmo quando favoráveis a uma BNCC.

Com o objetivo de compreender tomadas de posição dos entrevistados na relação com sua posição no campo do debate educacional, buscou-se

bem como uma assunção, pelos entrevistadores, do ponto de vista desfavorável à instituição de uma BNCC, em decorrência dessa relação social assimétrica entre entrevistadores e entrevistados, sobretudo quando se tratou de entrevistas com professores universitários, gestores e agentes da sociedade civil com forte presença na mídia. 
compor um largo espectro de pertença a esse campo: foram entrevistados 13 educadores da educação básica pública e privada, 23 dirigentes públicos, 45 professores universitários e 21 representantes de organizações da sociedade civil - fundações familiares e empresariais, associações e movimentos de advocacy e campanhas; três consultores e formadores de opinião que atuam junto a sistemas de ensino e órgãos públicos e privados, bem como junto à grande imprensa; dois representantes de órgão internacional e, por fim, cinco sindicalistas.

\section{Número de entrevistados por esferas}

\section{Escolar \\ - Gestăo pública \\ Sociedade civil \\ Universitária}

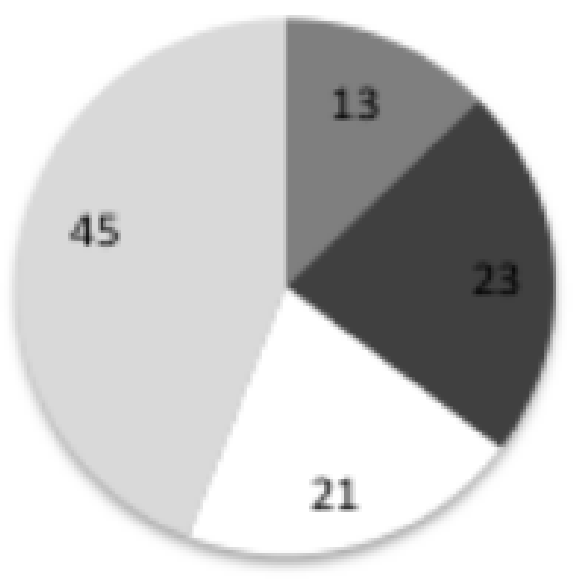

Fonte: Elaborado pelos autores.

O campo universitário está sobrerrepresentado em relação ao demais. Isso se deve, em primeiro lugar, ao fato de que, embora se tenha partido de uma lista prévia, utilizaram-se, para a seleção dos sujeitos, indicações dos próprios entrevistados. Em larga medida, foram indicados professores universitários, o que mostra seu prestígio, mesmo nos campos distintos do universitário. Outro fator foi a busca de agentes que tivessem posições contrárias à elaboração de uma base. A certa altura da coleta de dados, havia um predomínio indesejado de posicionamentos favoráveis, o que tornou necessário contrabalançar o grupo de entrevistados. Esses agentes 
com posições contrárias foram encontrados predominantemente no campo universitário, embora tenham sido encontrados também, ainda que em menor número, no campo da administração pública. Para a criação da primeira lista e das seguintes, empregaram-se distintas fontes: envolvidos no debate, conhecimento dos pesquisadores do campo, matérias de imprensa e trabalhos acadêmicos, consulta a currículos Lattes. Um terceiro fator será abordado no próximo parágrafo.

Todas as regiões do país estão representadas no grupo; no entanto, há maior concentração de entrevistados na região Sudeste e no Distrito Federal, em decorrência do número de profissionais e instituições do campo educacional dessas regiões que têm maior proximidade com a esfera do poder. Procurouse, no caso dos professores universitários, representar a variedade de áreas de conhecimento envolvidas na pesquisa educacional, outro fator responsável pela sobrerrepresentação de agentes desse campo. Foram entrevistados sete professores especialistas em currículo; dois da área de Fundamentos da Educação; oito que pesquisam a educação e diversidade étnica e cultural; 12 que se voltam para o ensino-aprendizado de disciplinas específicas (como língua portuguesa, matemática e história); e, por fim, seis que se voltam para o campo da avaliação, sete de política educacional e três de educação infantil.

Desse processo de seleção dos sujeitos decorrem importantes consequências para a análise dos dados. A primeira delas é a impossibilidade de fazer qualquer quantificação que extrapole os limites da amostra, uma vez que, a certa altura da seleção dos entrevistados, assumiu uma natureza intencional - a de aumentar a representação de tomadas de posição contrárias à elaboração da BNCC. Outra consequência é a dificuldade de realizar análises consistentes no interior dos grupos, dada a dispersão das posições sociais dos sujeitos em seu interior, bem como a pequena representação de certas posições - como, por exemplo, na esfera universitária, a dos pesquisadores das áreas de educação infantil e fundamentos da educação, bem como, também por exemplo, na esfera da sociedade civil, a de consultores $(n=2)$, de membros de sindicatos $(n=4)$, de fundações familiares $(n=2)$ e de fundações empresariais $(n=1)$.

A partir da análise das trajetórias dos sujeitos, construiu-se um espaço de posições (Figura 1) com base na acumulação de dois tipos de capitais, importantes no debate político, vale dizer, na capacidade de falar, de se fazer ouvir e de criar a crença na verdade daquilo que se enuncia. Trata-se, por um lado, do capital político - evidenciado, nas trajetórias dos agentes, pela 
ocupação de postos na administração pública, em comissões e conselhos, em consultorias a órgãos públicos, em instâncias decisórias ou, em síntese, por posições no campo do poder, especialmente no MEC, no Conselho Nacional de Educação e no Congresso Nacional. Trata-se também, por outro lado, do capital de autoridade acadêmica, acumulado por trajetória que demonstra reconhecimento acadêmico nacional e internacional, evidenciado por títulos, publicações e honrarias.

Os entrevistados foram identificados por códigos e situados no mapa de acordo com sua proximidade em relação a esses capitais, representados pelo centro. Quanto maior o capital político e acadêmico dos indivíduos, mais próximos foram posicionados em relação ao centro. 0 mapa foi dividido em quadrantes, um para cada grupo: academia, sociedade civil, sindicatos e gestão. 0 procedimento para construção do mapa baseou-se na atribuição de pontos numa escala em que representam a posse de capitais e, portanto, o poder de influência, bem como a posição de cada indivíduo e instituição.

Figura 1 - Mapa das posições dos entrevistados

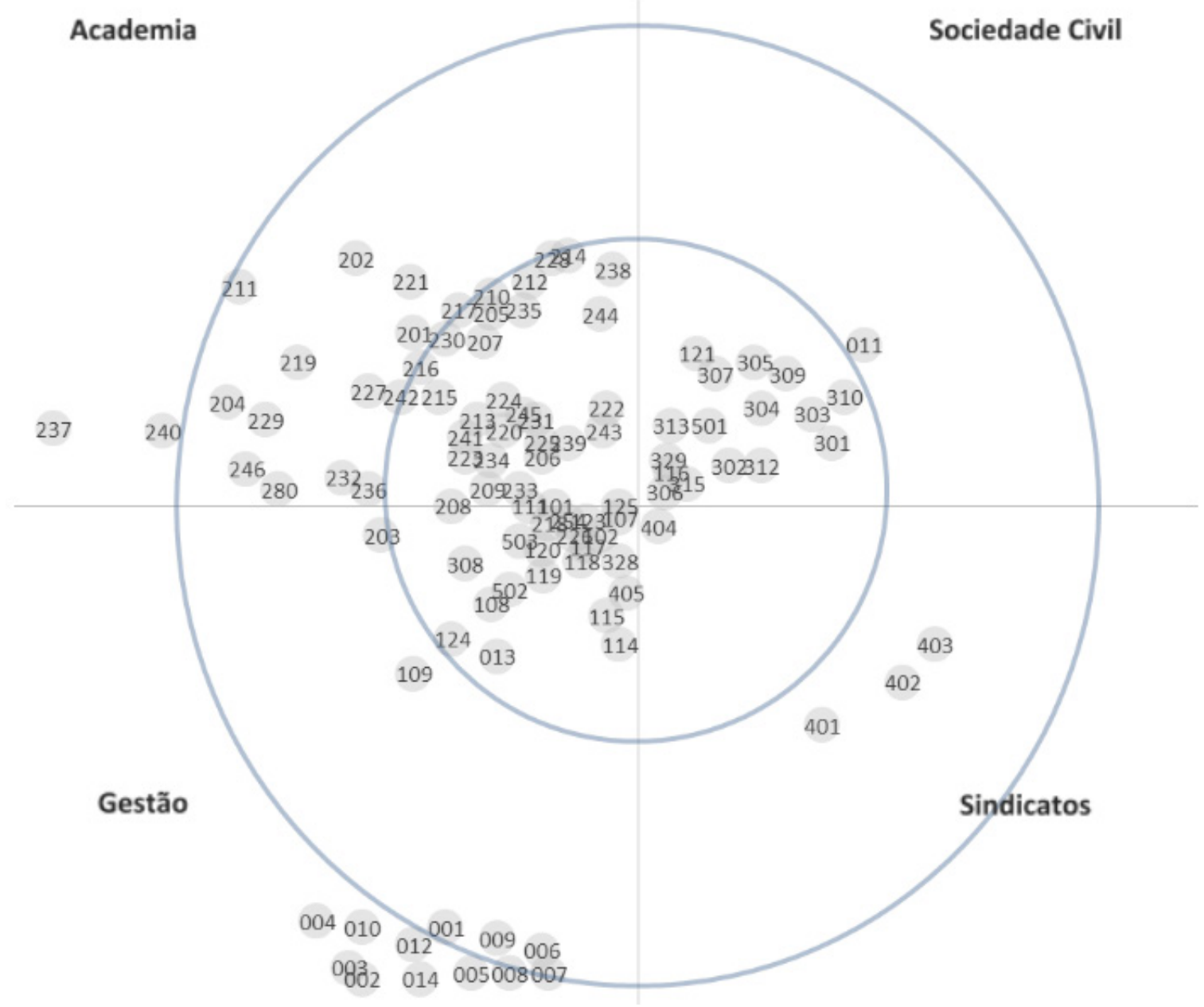

Fonte: Elaborada pelos autores. 
Como dizem respeito a grupos diferentes, os critérios para posicionamento dos agentes apresentam algumas variações. Eles são apresentados a seguir ${ }^{6}$.

Acadêmico (códigos 200) - Este agrupamento toma o prestígio no campo educacional como primeiro indicador; ele se baseia, grosso modo, no prestígio da instituição a que o agente está vinculado - que se expressa no maior tempo de funcionamento, na presença de programas de pós-graduação com boa avaliação pela Coordenação de Aperfeiçoamento de Pessoal de Nível Superior (Capes) e, de modo geral, na percepção da importância relativa das trajetórias, que se expressa no reconhecimento que só é possível pela partilha do habitus da academia. Por essa razão, a "escala de prestígio" dos agentes foi estabelecida pela análise de currículos Lattes (bolsas de produtividade, posição da carreira universitária, prêmios e publicações internacionais) e confirmada por um grupo de quatro pesquisadores da área educacional.

Mais próximos ao centro do mapa ficaram os acadêmicos que já ocuparam cargos nas instâncias decisórias, em função de seu capital acadêmico. Um segundo nível de influência é o das consultorias ao MEC. Mais para a extremidade esquerda foram situados os acadêmicos menos envolvidos na elaboração e implementação de políticas educacionais e, no alto, aqueles que se caracterizam como acadêmicos "puros". Na intersecção entre este quadrante e o da Sociedade Civil ficaram os entrevistados que, tendo feito carreira na academia, têm se dedicado a prestar consultoria para organizações não governamentais. Embaixo, junto à linha dos "gestores", estão os acadêmicos recém-ingressos no campo.

Gestão (códigos 100) - Este quadrante reuniu os dirigentes públicos, políticos, burocratas de carreira e secretários de Educação. O critério para a maior proximidade com o centro foi o âmbito de ação: se municipal, mais distante; se estadual ou federal, mais próximo. A construção do mapa evidenciou, porém, nas trajetórias do campo acadêmico, um trânsito considerável entre o quadrante acadêmico e o da gestão educacional: quanto mais próximos das posições de maior poder com relação a questões curriculares no campo acadêmico, maior a tendência dos agentes a ocupar cargos de direção executiva, o que deslocou alguns dos professores universitários para este quadrante. Aqui, ao contrário do campo acadêmico, a acumulação de capital ao longo do tempo deixa de contar: gestores com larga experiência, mas que

6 Para o posicionamento de cada agente foram consultados currículos, entrevistas dadas à imprensa e levadas em conta informações coletadas junto aos próprios entrevistados sobre eles e sobre terceiros. Os indicadores de cada posição relativa dos agentes, bem como suas fontes, variaram, evidentemente, de esfera para esfera. 
não possuíam um cargo que lhes permitisse o exercício de poder no momento das entrevistas ocuparam posições dominadas no campo.

Sociedade civil (códigos 300 e 500) - Neste quadrante, localizam-se especialmente os representantes do chamado "terceiro setor": ONGs, associações e consultores para grandes empresas educacionais e formadores de opinião, associações e movimentos de advocacy ou campanhas. Os próprios demandantes da pesquisa foram incluídos na pesquisa e submetidos à mesma objetivação que os demais pesquisados. A coloração ideológica desse campo possui um espectro bastante amplo. Mais junto ao centro estão as entidades que têm se dedicado a discutir diretamente a questão do currículo nacional, mais precisamente da BNCC, e que dispõem de mais recursos para fazer pressão nas instituições centrais. Neste campo, capitais de natureza econômica e social tenderam a favorecer posições dominantes e, portanto, mais próximas do centro do quadrante.

Sindicatos (códigos 400) - Estes foram hierarquizados segundo seu nível de abrangência: os federais antes que os estaduais e estes antes que os municipais.

Professores de ensino fundamental e gestores de escolas particulares (códigos 01 a 08) - As entrevistas indicaram que esses professores das escolas públicas não constituem agentes com influência na negociação dos projetos curriculares, o que é verdadeiro também para os gestores das escolas particulares de elite. Este é o grupo que se encontra no canto inferior esquerdo da Figura 1, próximos do grupo de gestão, mas não incluídos nele, pois, além de possuírem uma natureza distinta, estão distantes dos círculos de poder e alheios ao debate sobre a questão do currículo, especialmente sobre a BNCC. Embora tenham opiniões sobre os processos de centralização e padronização dos currículos, bem como sobre a BNCC, o que as entrevistas revelam, para ambos os grupos, é que a questão da Base se colocou para eles pela primeira vez.

Uma última observação de natureza metodológica, antes de passar ao exame dos dados: a análise das tomadas de posição é de natureza qualitativa. Realizou-se uma análise de conteúdo das entrevistas de cada agente de cada grupo, de modo a construir suas tomadas de posição - compreendidas aqui como construções abstratas. Essa análise não autoriza, portanto, qualquer generalização ou quantificação, assim como conclusões semelhantes a: “metade é a favor" ou “65\% são contra”. O que se apreende aqui são pontos de vista que podem ser, no caso de grupos com maior representação, com 
base numa análise feita a partir de um objeto construído teoricamente, relacionados a posições ocupadas no campo educacional.

Um contínuo de tomadas de posição: dos absolutamente contrários aos absolutamente favoráveis a uma centralização e padronização dos currículos

Para analisar as entrevistas, fez-se uma primeira linha de corte: quando perguntados a respeito de sua opinião sobre o estabelecimento de um currículo nacional no país, os entrevistados responderam se eram favoráveis ou contrários (ver Figura 2).

Foi esse posicionamento inicial que gerou a classificação "contrários" e "favoráveis".

Figura 2 - Entrevistados a favor ou contra um Currículo Nacional

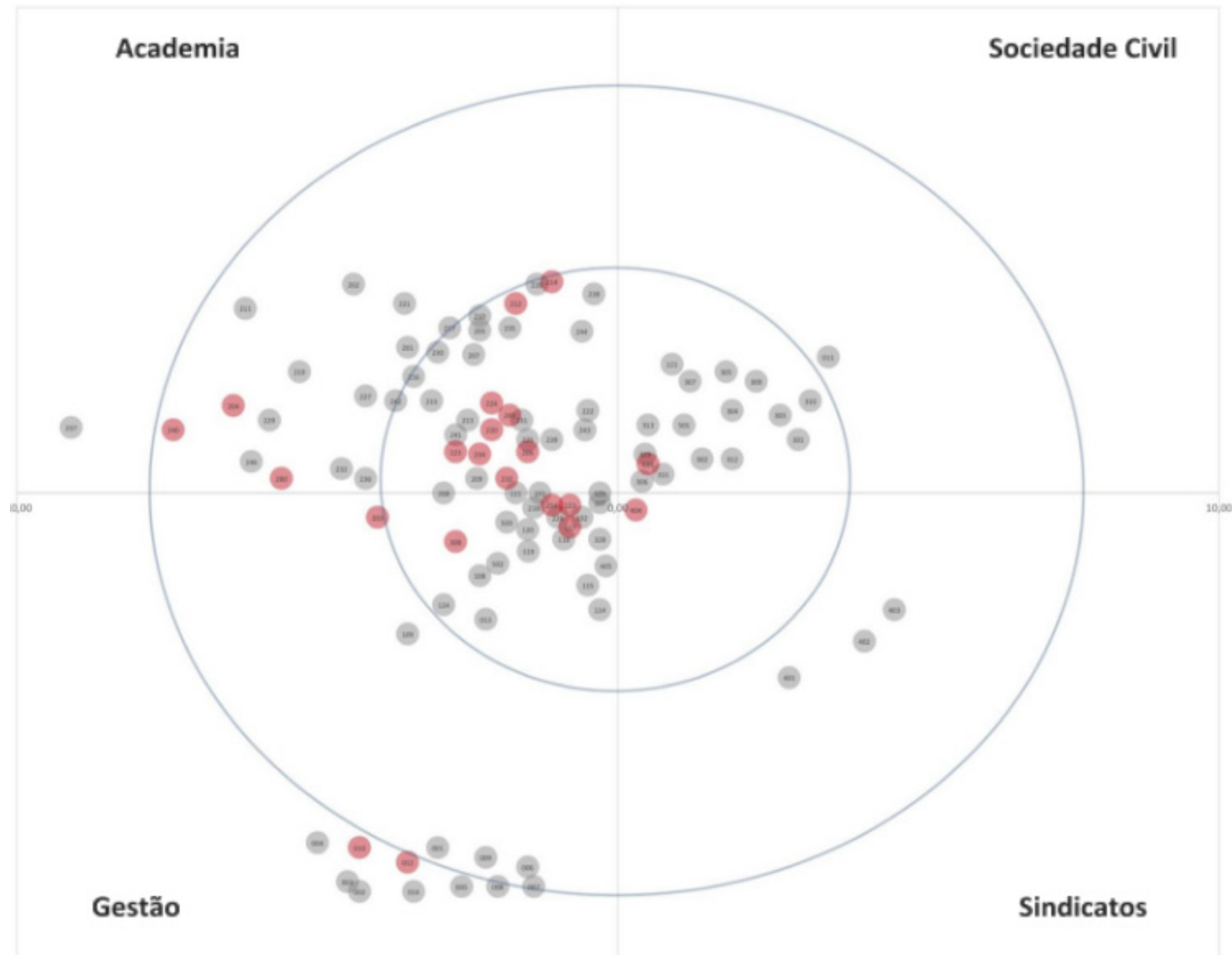

Fonte: Elaborada pelos autores. 
Pode-se observar que ocorre maior concentração de pontos de vista contrários a uma padronização curricular nacional ao redor das instâncias decisórias. Apesar disso, se também for levado em conta o conjunto de tomadas de posição favoráveis junto às mesmas instâncias, o que a Figura 2 parece evidenciar é uma forte correlação de forças, especialmente nas posições mais influentes dos campos da gestão e da academia. Nesse último caso, é interessante notar que as tomadas de posição desfavoráveis a uma centralização e padronização curricular se originam da área do currículo e de política educacional, sobretudo, sendo praticamente ausentes nas áreas de ensino de disciplinas e de avaliação educacional, independentemente do grau de influência e, portanto, dos capitais acumulados e do tempo de ingresso no campo. Parece que essa oposição reproduz uma oposição maior que divide o campo da academia: a divisão entre especialistas em currículo e em política educacional e especialistas no ensino de disciplinas. Isso talvez expresse a mesma divisão, nas faculdades de Educação, que separa os departamentos ditos "teóricos", de políticas, currículo e fundamentos, de um lado, e o departamento de prática e metodologia de ensino, de outro, e, desse modo, a divisão entre teoria e prática que é constitutiva do campo. Parece também que a divisão reproduz, dada a maior adesão dos especialistas em avaliação educacional, a profunda oposição que marca hoje o campo educacional entre os agentes sobre o modo de regulação do sistema educacional público.

Ao que tudo indica, portanto, o fator "disciplinar" e as disputas em torno dos modos de regulação parecem ter um peso maior na construção das disposições favoráveis ou contrárias à centralização e padronização dos currículos do que outros fatores relacionados à sua posição social. Evidentemente, uma exploração mais detalhada do campo universitário educacional é necessária para o aprofundamento dessas hipóteses.

No caso da gestão, trata-se de um grupo de agentes com forte poder de oposição, pois pertence aos quadros das instâncias decisórias. Um dado importante é que esse grupo se articula em torno de agentes que migram do campo da universidade. É desse mesmo grupo que se origina a única oposição que surge no campo da sociedade civil, manifestada por agente que, por sua vez, migra do campo da administração pública para esse campo e nele investe as disposições compartilhadas pelo grupo. o campo da sociedade civil, portanto, independentemente da coloração ideológica dos agentes que possui um arco bastante amplo -, assume tomadas de posição bastante uniformes e favoráveis a uma BNCC. Voltando ao campo da gestão, um dado importante é que, apesar do grupo de agentes contrários, há outros favoráveis 
dentro do próprio MEC e de outras instâncias decisórias e, especialmente, nas posições em que se poderia crer que não se encontrasse - dado o discurso de uma suposta perda de autonomia dos entes federados pela centralização curricular -, entre secretários estaduais e municipais de Educação.

Essa oposição entre favoráveis e desfavoráveis, porém, tende a se tornar mais complexa após uma análise aprofundada das entrevistas: ela mostra que, embora haja uma polarização entre os agentes, eles podem assumir argumentos semelhantes mesmo tendo tomadas de posição opostas.

Por um lado, muitos dos opositores a uma forte centralização e padronização expressa por um currículo nacional admitem a possibilidade de uma orientação curricular central desde que constituída por um mínimo de aqui a terminologia é movediça - "expectativas"/“conteúdos”/“direitos de aprendizagem"/“objetivos”, e com a condição de que se contemple a diversidade cultural que caracteriza o país, bem como a diversidade de práticas e experiências pedagógicas existentes. Por outro lado, muitos dos que são favoráveis a um currículo nacional fazem também a mesma ressalva - isto é, admitem essa centralização e padronização desde que seja relativamente branda: deve apresentar um mínimo de "conteúdos" e contemplar a questão da diversidade. Disso resulta que muitas tomadas de posição indicadas no mapa como contrárias ao currículo nacional terminam por ser coincidentes com as favoráveis quando os argumentos são examinados em detalhe, tendo um conjunto de "conteúdos" mínimos e o respeito à diversidade como denominadores comuns.

Essas nuances podem ser representadas como um contínuo (figuras 5 e 6, comentadas mais à frente), em função dessa percepção de inexistência de uma separação claramente definida entre os que se posicionaram de forma contrária e os que se posicionaram de forma favorável a um currículo nacional. Desse modo, a noção de contínuo, de um deslocamento gradual, que vai dos que são absolutamente contrários a qualquer definição curricular ou padronização nacional até os que consideram que se deve definir com detalhe tudo o que é ensinado nas escolas para orientar inclusive a formação de professores, parece ser adequada. É importante observar que os polos do contínuo - pontos de vista fortemente favoráveis ou contrários - possuem pouca representatividade no conjunto e são quase todos de pessoas vinculadas à academia, podendo-se supor que esse campo seja o espaço por excelência das lutas em torno do currículo. 
Conforme se depreende da Figura 3, a pesquisa indica quatro categorias de pontos de vista e argumentos entre os que se declararam contrários a um currículo nacional: (i) aqueles completamente contrários; (ii) aqueles que consideram a discussão desnecessária, porque este já existe e precisa ser implementado; (iii) aqueles que o aceitariam se fosse constituído por um núcleo mínimo elaborado com base em conteúdos que se reportam à diversidade; (iv) os que o aceitariam se fosse constituído por um núcleo mínimo de conteúdos universais, complementado localmente por conteúdos relativos à diversidade local e ao que por comodidade se convencionou chamar "minorias".

Figura 3 - Detalhamento das posições dos entrevistados contrários à Base Nacional Curricular Comum

\section{Academia}

Sociedade Civil

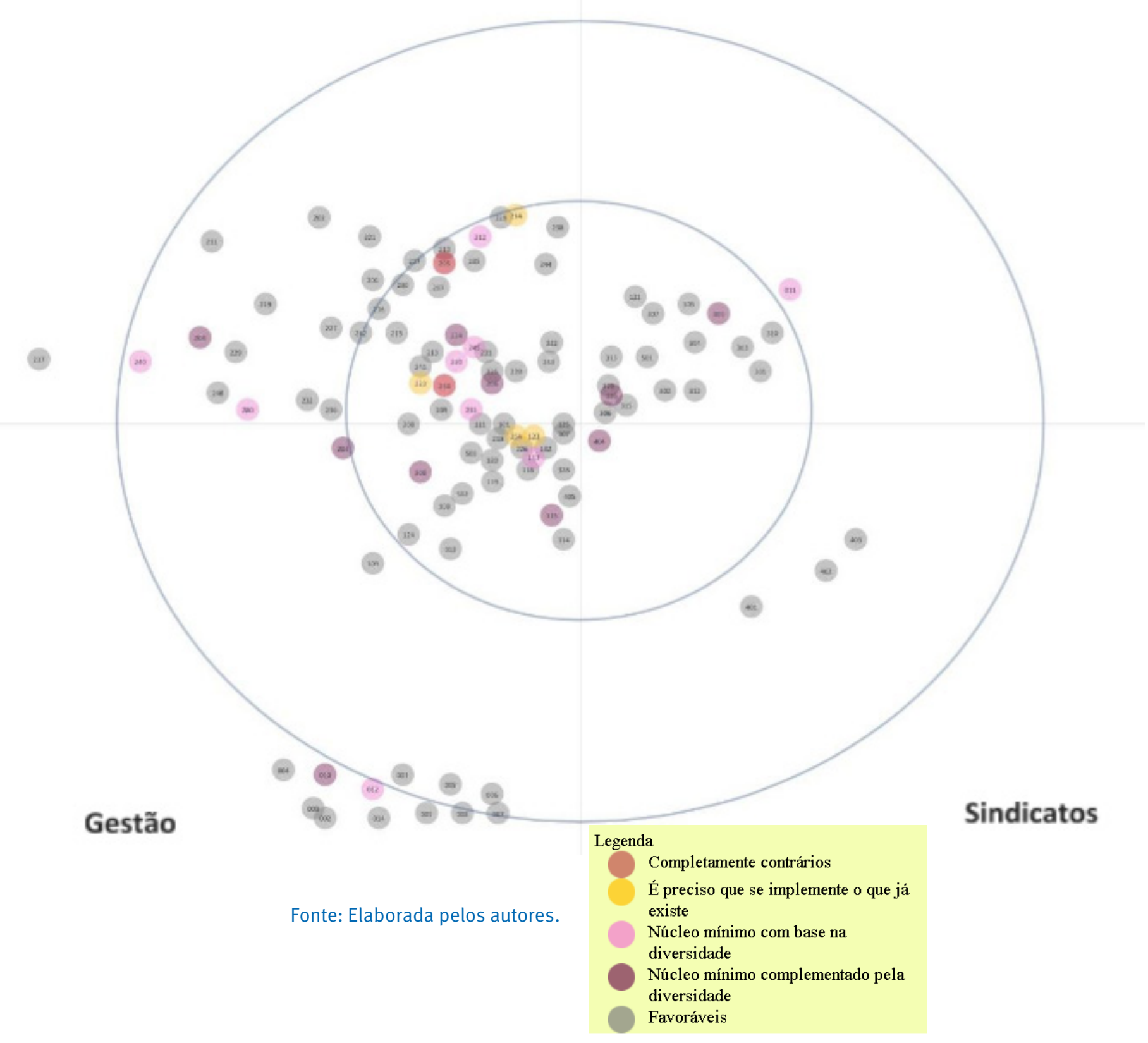


Para aqueles contrários a um movimento de centralização e padronização dos currículos (com a exceção dos que consideram o debate desnecessário), há dois conjuntos de argumentos centrais. Ambos se baseiam na ideia de que a padronização dos currículos envolve também um empobrecimento - com fortes consequências políticas - tanto da diversidade das práticas e experiências pedagógicas em curso, quanto da diversidade da vida de professores e alunos, que podem encontrar na escola um espaço para a construção de suas identidades, para saber de si - de sua condição e história, de invenção de seu projeto de futuro - e dos outros. Ambos buscam romper com a histórica função homogeneizadora da instituição escolar, buscando pensá-la como uma instituição que promove a diferença. Nesse quadro, os dois conjuntos de argumentos negam a ideia de um projeto de nação único que estaria subjacente à proposição de um currículo nacional. De acordo com o primeiro conjunto de argumentos, a negação é necessária porque estão em disputa, no país, diferentes projetos de nação, expressos por distintas práticas pedagógicas de grupos sociais e de redes de ensino que seriam anuladas pelo movimento de padronização curricular central - daí suas graves consequências políticas, especialmente para as forças sociais que se opõem hoje a grandes interesses econômicos das camadas dominantes. De acordo, porém, com um segundo grupo de argumentos, a negação de um projeto de nação pressuposto num currículo nacional seria necessária pela própria natureza anacrônica da ideia de um projeto nacional - um ideal da modernidade - incapaz de sobreviver às forças centrífugas das identidades pós-modernas, diversas e móveis, que demandam um currículo baseado não na transmissão de um conjunto de conhecimentos comuns, mas na construção de experiências cujo centro é a possibilidade, na escola, de produção das identidades diversas em confronto com a norma. Por essa razão, nesse quadro argumentativo, não faz sentido possuir um núcleo comum, em geral compreendido como conhecimentos "universais", ao qual se acrescentariam conteúdos "locais" ou relacionados a grupos sociais compreendidos como "específicos" ou "minorias”: indígenas, quilombolas, negros, não heterossexuais, por exemplo, pois esses conteúdos seriam "penduricalhos", não fariam parte do "comum", seriam conteúdo sobre os "diversos" para os próprios “diversos".

Por fim, para os dois grupos de argumentos é a escola, em seu cotidiano, o local por excelência da construção do currículo, não como um documento normativo, mas como uma prática coletivamente construída.

Uma categoria que se destaca entre os contrários à centralização e padronização curricular remete à inutilidade da discussão do tema, uma vez que, segundo 
alguns entrevistados, já existiria um currículo nacional. Muitos chamam a atenção para o controle do currículo exercido, progressivamente, desde os anos 1990, pelas avaliações em larga escala. Elas teriam promovido não apenas uma definição de conhecimentos a ensinar, mas também uma radical redução do currículo do conjunto de conhecimentos, valores, modos de ser e de fazer envolvidos no processo educativo, a um conjunto de competências a serem desenvolvidas. Essas competências, por sua vez, foram reduzidas a capacidades abstratas de leitura e matemática e, ao se estabelecer uma estreita relação entre sua aquisição e uma idade ou um período da escolarização, contribuído para a exclusão ou para a estigmatização dos alunos que, muito afastados do universo escolar, não alcançavam essas "expectativas". Outros entrevistados, porém, reconhecem a existência de um currículo nacional, não como um currículo de fato, já em ação, mas como um documento oficial. Para eles já existem documentos oficiais centrais que padronizam os currículos e programas de ensino, mas esses documentos não foram efetivamente implementados, como, para alguns, os Parâmetros Curriculares Nacionais (PCN) e, para outros, as Diretrizes Curriculares Nacionais (DCN). Para estes, há uma expectativa excessiva na elaboração de documentos curriculares como motor de mudança educacional. Mais importante seria investir na carreira e na formação dos docentes, em suas condições de trabalho, na infraestrutura escolar, na organização e estrutura dos sistemas educacionais.

Os pontos de vista mais ao centro do contínuo, ainda no âmbito dos contrários ao estabelecimento de um currículo nacional, tendem a admitir, porém, certa centralização e padronização, desde que se considere uma série de questões que dizem respeito, sobretudo, à diversidade. Ou seja, consideram que, caso esses processos ocorram, deve-se estabelecer um núcleo mínimo de conhecimentos comuns, de fato essenciais para os processos de escolarização, mantendo a maior autonomia possível para as escolas e para os sistemas de ensino contribuírem com aquilo que consideram específico. Quando instados a definir o que seria compreendido por esse núcleo mínimo, aparece uma posição que defende que seja construído a partir da diversidade cultural e social. Aqui, duas visões se manifestam: por um lado, aquela que, como se evidenciou mais acima, incorpore o local e a visão das supostas minorias e o conflito de pontos de vista como parte do conteúdo curricular; por outro lado, aquela que defende a superação de uma visão hegemônica da história, da geografia, do ensino de língua, que é, afirma-se, geralmente formulada em ambientes urbanos, de matriz europeia. Tais pontos de vista defendem, de certo modo, uma inversão das relações de poder que, segundo essa perspectiva, estão envolvidas na construção do currículo, propondo um processo que vá "de baixo para cima”. 
No contínuo de argumentos e pontos de vista, a ideia de que é positivo que a escola tenha uma rica interlocução com as realidades locais e a diversidade sociocultural não é exclusiva dos agentes que fazem oposição a um currículo nacional. Ela é também mobilizada por muitos dos entrevistados favoráveis a processos de centralização e padronização curricular, particularmente pelos que podem ser chamados de "moderados" nas posições centrais do contínuo. Da parte desses últimos, há bastante receio de que esses processos sirvam para reforçar desigualdades existentes no país.

É importante ressaltar que, tal como se observa na imagem que representa o contínuo dos argumentos (figuras 5 e 6), existe uma sobreposição entre o bloco mais à esquerda do grupo contrário a padrões nacionais e o bloco mais à direita do grupo favorável. Em outras palavras, se as figuras 5 e 6 fossem postas em linha, teríamos uma progressão que iria dos absolutamente contrários a qualquer padronização, e que tendem a compreender a escola como o espaço por excelência de produção do currículo, aos absolutamente favoráveis ao máximo de padronização, defensores de um currículo único e detalhado. Entre um extremo e outro há uma gradação, baseada na admissão de algum elemento comum para orientar as escolas, bem como no grau de importância atribuído ao local e à diversidade.

O contínuo favorável contempla, no que se refere à extensão do currículo, duas grandes posições que se desdobram: a do "núcleo mínimo" e a do "núcleo comum". Essa diferenciação remete à extensão dos "conteúdos" que seriam objeto de padronização nacional. Os que defendem um "núcleo comum" consideram que este não deve contemplar apenas o mínimo de conhecimento necessário, uma vez que este acabaria se tornando a totalidade do currículo nas regiões em que as escolas são mais precarizadas. Quanto mais a tomada de posição é a favor da centralização e padronização dos currículos, maior é a defesa de um "núcleo comum"; quanto mais moderada é a tomada de posição, maior é a defesa de um núcleo mínimo. Nesse último caso, a mesma preocupação com escolas e redes de ensino aparece: no quadro das avaliações de larga escala, o foco em resultados levaria essas escolas e redes ao abandono de temas locais e significativos porque promoveria a priorização dos conteúdos relativos a habilidades mais diretamente cobradas nos testes.

Quanto mais forte é a adesão a um currículo nacional - sempre aqui compreendido como processos de centralização e padronização -, menor é a adesão a "conteúdos" ou experiências relacionados à diversidade, bem como à iniciativa dos entes federados, das escolas e docentes na 
construção do currículo, seja na afirmação de sua autonomia relativa, seja no estabelecimento de elos com contextos locais. O contrário é também verdadeiro: quanto menor a adesão, maior a afirmação de um currículo que tem como centro a diversidade e o local e com maior abertura à iniciativa dos entes federados e dos educadores.

Essas duas tomadas de posição extremas orientam-se por certa busca de justiça. Ambas parecem partir de um princípio de justiça distributiva: o conhecimento, compreendido como um bem que deve ser igualmente distribuído. Para uns, essa justiça distributiva tende a assumir um caráter meritocrático: trata-se de um saber universal, a ser distribuído a todos igualmente, para que todos tenham iguais chances. Daí uma defesa de que esse currículo seja invariável em todo o país, não importando o público, o local ou a dependência administrativa, devendo ser o mesmo para escolas públicas e privadas. Para outros, a justiça assume um caráter mais equitativo: dar o mesmo aos diferentes, esperando os mesmos resultados, é uma forma de injustiça; um núcleo comum, por exemplo, que define em pormenor e a priori formas de progressão e de compassamento (BERNSTEIN, 1990), desconsidera as relações entre os objetos de conhecimento e o universo sociocultural do aluno, acabando por transformar a diferença diante do saber em desigualdade diante do saber; em outras palavras, em deficiência. Nas posições mais moderadas, a justiça assume ainda um caráter simbólico e não apenas distributivo: trata-se também - ao trazer a cultura daqueles tidos como "outros" - de uma política de reconhecimento e de valorização. 
Figura 4 - Conjuntos dos posicionamentos favoráveis

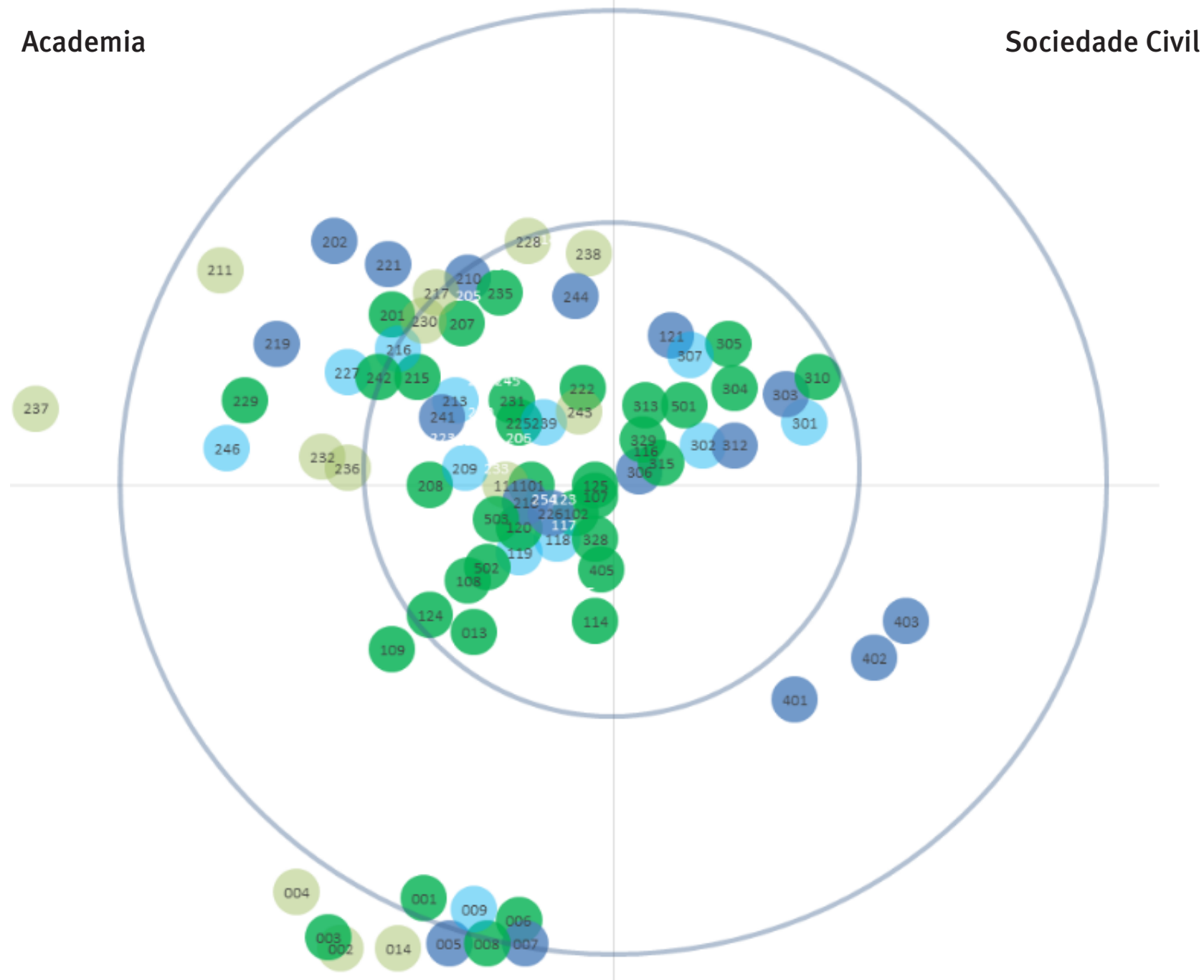

\section{Legenda}

Currículo a partir de conhecimentos comuns, preservando a diversidade Definição a partir das realidades locais

Favoráveis a um núcleo mínimo que seria complementado localmente O mesmo ensino para todos

Fonte: Elaborada pelos autores. 
Figura 5 - Contínuo de argumentos dos entrevistados contrários à padronização curricular
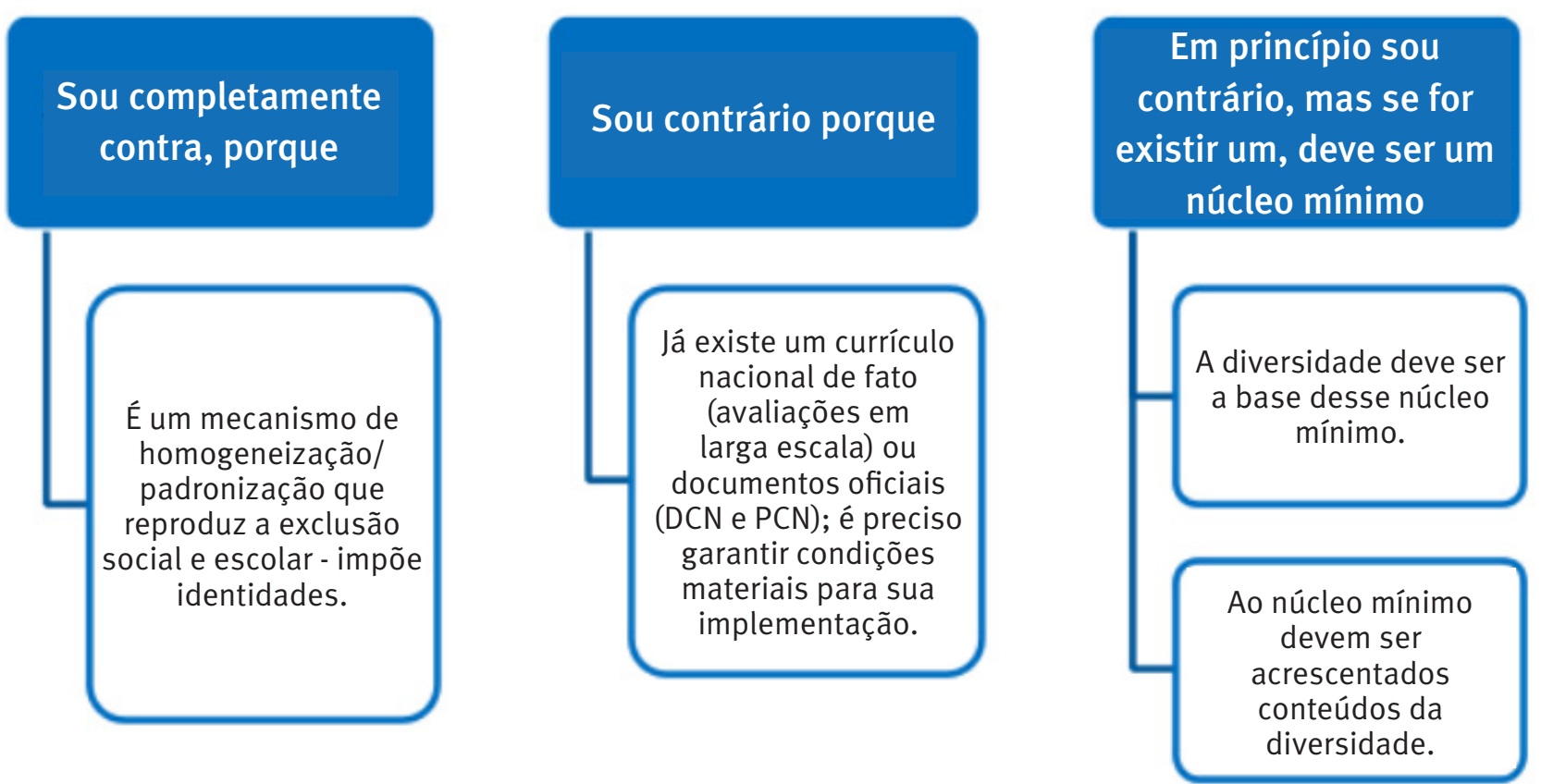

Fonte: Elaborada pelos autores.

Figura 6 - Contínuo de pontos de vista dos entrevistados favoráveis à padronização curricular
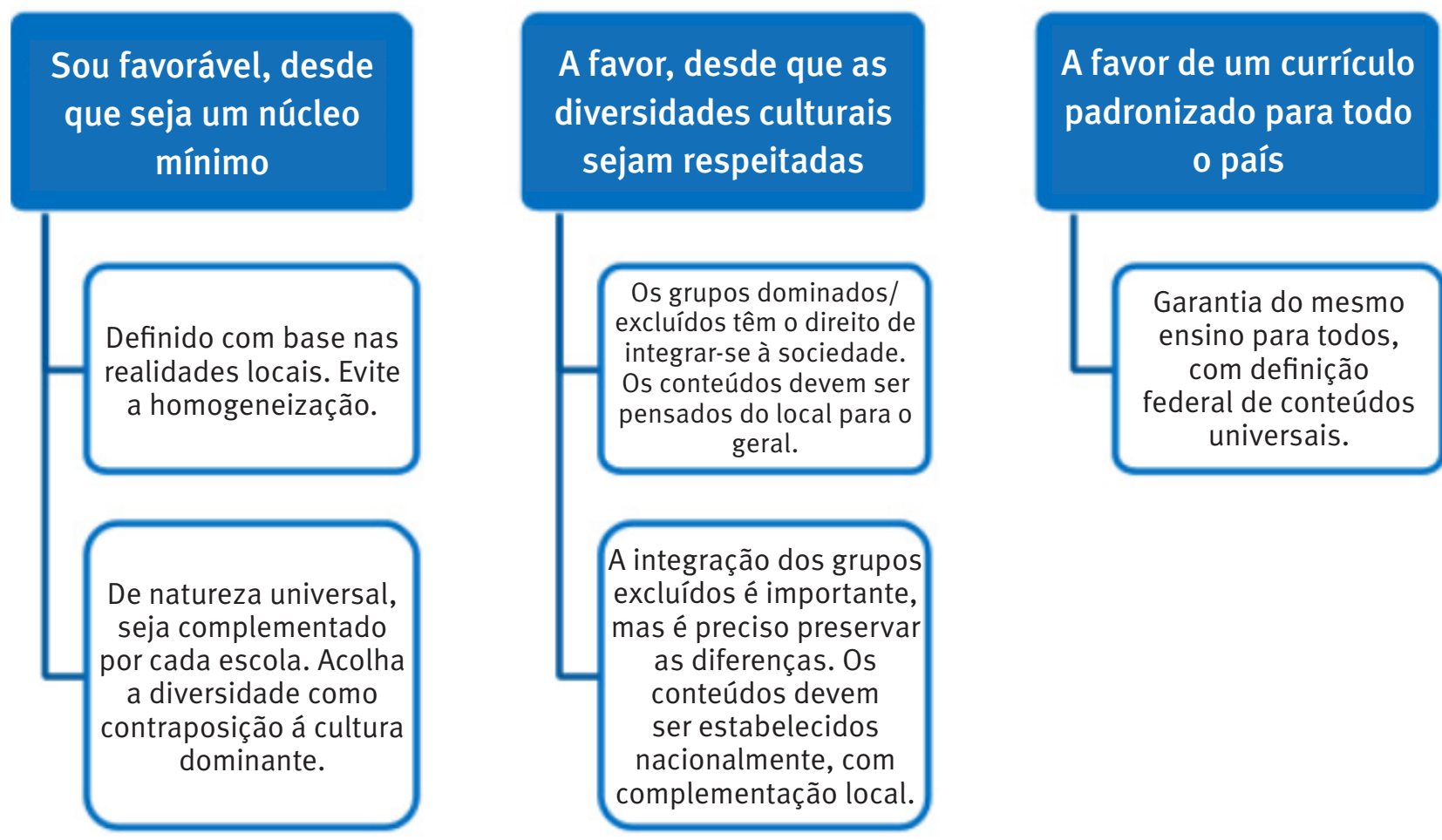

Fonte: Elaborada pelos autores. 
A análise da distribuição das tomadas de posição favoráveis no campo do debate educacional (figuras 4, 5 e 6) evidencia fenômenos interessantes. Primeiro, tanto os administradores quanto os membros da sociedade civil parecem optar por uma espécie de solução de compromisso entre as tomadas de posição extremadas e moderadas: há certa uniformidade, nas duas esferas, na defesa por um currículo nacional baseado num núcleo composto por conhecimentos comuns, mas que respeita a diversidade. Tratase de uma uniformidade que esconde, porém, uma grande heterogeneidade, pois a categoria argumentativa é, muitas vezes, uma estratégia discursiva que esconde uma forte adesão, na realidade, a orientações curriculares centralizadas e padronizadas, organizadas em torno do princípio do mérito, especialmente de agentes posicionados no campo da sociedade civil.

Por essa razão, a disputa entre tomadas de posição é maior no chamado campo da sociedade civil, no qual as instituições situadas mais à esquerda no campo do ideário político e pedagógico tendem a estar mais abertas ao local e ao diverso. Nenhuma das instituições dessa esfera, tampouco nenhum dos agentes da esfera da gestão assume abertamente uma tomada de posição extrema, de que todas as escolas brasileiras devem seguir uma única orientação curricular. Apesar disso, muitos agentes defendem essa posição, mas ela aparece de eufemizada, por meio da defesa de um núcleo comum e do respeito à diversidade.

É no campo acadêmico que essa tomada de posição se manifesta de modo aberto. Não foi possível apreender entre os favoráveis traços comuns relevantes a uma leitura sociológica: são docentes com distintos graus de prestígio, de diferentes áreas da educação, com diferentes tempos de ingresso no campo. É interessante que a tomada de posição, como se verá mais à frente, é compartilhada com docentes da educação básica. O sentido dessa tomada de posição, porém, é também variado e distinto daquele encontrado no campo da sociedade social: o que se encontra no campo acadêmico é defesa de uma escola única, de um lado, ou, de outro, de uma escola que transmite uma "cultura comum", sempre como fator de equidade.

Tendo em vista o conjunto dos agentes favoráveis a processos de centralização e padronização, entretanto, o ponto de vista que predomina é o moderado: deseja-se que a definição seja feita a partir de realidades locais e que se constitua em torno de um núcleo mínimo, completado localmente. Aqui tampouco se podem apreender elementos comuns aos agentes em torno de uma ou outra posição. 
A fala dos entrevistados com trajetórias na gestão educacional é marcada pelas questões de ordem prática e administrativa, ou seja, mesmo que falem com base em princípios, enfatizam mais claramente os embates políticos e as questões relativas à implementação de um currículo nacional. Boa parte deles defende, como já se indicou, a ideia de um núcleo comum, respeitada a diversidade, mas as entrevistas expressam claramente o desejo de uma definição mais detalhada de objetivos e conteúdos.

Os gestores de escolas particulares de elite (códigos 09 a 14 na Figura 4) evidenciaram, pela natureza das respostas, distância do debate tal como é feito pelas outras categorias de entrevistados. Metade deles se posicionou contrariamente a qualquer tipo de padronização curricular e o restante (com uma exceção) defendeu a flexibilização de um eventual currículo nacional para permitir a adequação às peculiaridades locais. No caso desse grupo, isso diz respeito tanto à possibilidade de realizar experiências diferenciadas de ensino, em termos de metodologia e organização dos conteúdos, como ao atendimento de públicos específicos no mercado educacional.

Os pontos de vista advindos de membros de sindicatos mais influentes se estruturam mais fortemente contrários à padronização curricular, utilizando o argumento da preservação da autonomia de trabalho dos professores, enquanto que os menos influentes admitem uma centralização e padronização curricular. Trata-se, provavelmente, de um efeito de posição do campo: quanto mais próximos dos sistemas de ensino, mais favoráveis a esses processos (com adequações às realidades locais).

Os discursos dos professores de educação básica mostram distância do debate, evidenciando que as questões não fazem parte de seu horizonte de problemas cotidianos. Essa situação fez com que suas entrevistas tenham sido qualitativamente diferentes das demais. Acredita-se que, para que os pontos de vista desses professores com relação a um currículo nacional possam ser devidamente mapeados, seja necessário desenvolver uma pesquisa com uma amostra representativa e/ou com outro tipo de abordagem, que diga mais respeito às implicações cotidianas de distintas perspectivas curriculares. As entrevistas indicam que a questão curricular chega a eles mediadas pelas diferentes instâncias administrativas e políticas, de modo que não é percebida como proposta de uma política pelos professores em seu cotidiano. No entanto, dentro dos limites assinalados, esses entrevistados expressaram um ponto de vista a favor de um currículo nacional, ora pensado como apoio para as suas práticas, ora como grandes linhas dentro das quais eles poderiam fazer funcionar seus estilos didáticos. 


\section{CONSIDERAÇÕES FINAIS}

A análise dos dados mostrou haver uma contraposição demarcada entre aqueles que se disseram contrários e os que se disseram favoráveis ao estabelecimento de um currículo nacional no país. Essa contraposição, porém, esconde um conjunto de consensos. Mesmo junto àqueles que se disseram inicialmente contrários, há condições que se estabelecem para a aceitação de uma BNCC. Os mais demarcadamente contrários, que disseram não aceitar de modo algum qualquer padronização, encontram-se predominantemente na academia. Argumentos vinculados ao modo como a padronização - currículo nacional ou BNCC - lidará com a questão da diversidade estruturam as posições tanto do grupo que se declarou inicialmente favorável tanto do que se declarou contrário, num contínuo de argumentos que vão da defesa da autonomia completa da escola e do professor até a padronização de todos os conteúdos, de modo detalhado, por meio de um documento nacional. Na maior parte dos pontos de vista, qualquer desses caminhos precisa dar respostas à questão da diversidade.

0 entendimento que emergiu de forma mais forte na pesquisa (em termos do número de pessoas que o defendem, seu grau de influência e a distribuição desses representantes nos diversos grupos), é o de que uma BNCC deveria corresponder a uma parte significativa de um currículo nacional (não um “núcleo mínimo", que poderia ser interpretado como o "máximo a ser ensinado", restringindo processos de escolarização). Ou seja, um documento de BNCC deveria conter predominantemente conhecimentos de natureza universal, necessários para todos, a serem complementados por conteúdos específicos, definidos localmente (no estado, no município ou na escola). Com menor peso, encontramos a defesa da inclusão de conteúdos vinculados à diversidade no próprio texto da base.

A análise dos dados indica a presença entre os entrevistados de, pelo menos, dois tipos de argumentação em confronto: uma, de raiz sociológica, que se concentra na crítica ao papel reprodutor das relações de dominação que é feito pela escola, num processo que vem excluindo as camadas desfavorecidas da população. Deste ponto de vista, os efeitos sociais que a escola produz dizem respeito à natureza dessa instituição numa sociedade capitalista. A outra posição parte da concepção do direito à educação como direito à integração social, que é uma dívida da sociedade brasileira com relação aos grupos excluídos. Nesse caso, trata-se de identificar os pontos no sistema que produzem o "mau funcionamento" da escola e corrigi-los. Um currículo 
bem estruturado seria um passo fundamental para dar racionalidade ao sistema. Ambas as posições coexistem na fala de entrevistados que possuem posições mais moderadas dentro de um espectro que vai dos radicalmente contra qualquer padronização curricular aos radicalmente favoráveis a um currículo nacional ou a uma BNCC.

Evidenciou-se que não há clareza em relação às definições de currículo. Foi comum um mesmo entrevistado iniciar a entrevista usando um determinado conceito e terminá-la usando outro como se significasse o mesmo. Notou-se ainda que alguns acreditam que documentos oficiais como os PCNs ou DCNs são um conjunto de conteúdos e expressam o currículo nacional. Algumas visões incluem as condições materiais como fazendo parte de um currículo e outros avaliam ser apenas a lista de conteúdos a serem ensinados nas disciplinas.

Apesquisa remete a outras indagações. Sobretudo quando esses pontos devista são analisados à luz de discussões mais amplas sobre meios de enfrentamento das desigualdades. No imaginário de boa parte daqueles envolvidos com a definição ou discussão de políticas curriculares no país, predomina a noção de que, dada a grande diversidade do Brasil, o enfrentamento da desigualdade, da exclusão ou da dominação deve prioritariamente se dar pelo respeito à diversidade. Dubet (2012) afirma haver duas matrizes de políticas contra a desigualdade nas sociedades democráticas contemporâneas que "se combinam, se justapõem e se enfrentam", de modo semelhante ao que foi visto nos argumentos das entrevistas analisadas. Uma se baseia na igualdade de posições e outra na igualdade de oportunidades. Para o autor, as políticas centradas no objetivo de ampliar a igualdade de oportunidades de modo que indivíduos historicamente vinculados a grupos sociais desfavorecidos possam participar e se inserir socialmente de forma justa têm dominado a cena nos últimos anos. Têm sido preteridas as iniciativas cujo princípio é a igualdade de posições que focalizam, na perspectiva do autor, a distribuição entre todos de recursos valorizados socialmente independentemente da discussão sobre o mérito do indivíduo, suas qualidades ou vínculos a determinados grupos sociais. Entretanto, o autor afirma que os países que adotam prioritariamente políticas com base no princípio da igualdade de posições são menos desiguais que aqueles que apostam na igualdade de oportunidades.

Essas afirmações de Dubet são instigantes porque ajudam a refletir sobre que tipo de preocupação deve ser central para definições curriculares em um país tão desigual e tão diverso quanto o Brasil, que tem pouco 
acúmulo histórico e político tanto no que tange à diminuição das distâncias entre as posições sociais, como também no reconhecimento e garantia da igualdade de oportunidades para os indivíduos, sobremaneira os mais pobres, os negros e os indígenas. Devemos concentrar nossos esforços na distribuição de conhecimentos definidos como necessários para todos? Devemos ter como questão central o respeito à diversidade para fazer essa distribuição, fortalecendo as identidades dos grupos sociais historicamente desfavorecidos? Ou seria mais profícuo combinarmos, de algum modo, essas duas perspectivas? 


\section{Curriculum centralization and standardization: positions and position-takings}

Abstract: The object of this exploratory study is the construction of the space of position-takings and arguments about the debate on the process of curriculum centralization and standardization in the country, through a National Common Basis. It aims, moreover, to examine the relationships between positiontakings and arguments, on the one hand, the social position of the individuals interviewed, who participate in the public debate on the subject, yet working in different fields of the social world. Thus, we situated the object of research in a sociological framework inspired by Bourdieu, mainly regarding his theory about social fields. For this study, we conducted interviews with 103 persons who generally participate in the educational debate (universities, civil society, primary education, unions, public management) in all regions of the country, using a semi-structured interview script, from late 2013 to early 2014. The analysis allowed constructing the position-takings related to some of the individuals' social positions, particularly their position both in their field and in relation to political decision-making spheres.

Keywords: Curriculum. National Common Basis. Educational policy. 


\section{Centralización y estandarización de los currículos: posiciones y tomas de posición}

Resumen: Este trabajo, de naturaleza exploratoria, tiene por objeto la construcción del espacio de las tomas de posición y argumentos sobre el debate con respecto al proceso de centralización y estandarización curricular en Brasil, mediante una Base Nacional Curricular común. Asimismo, tiene el objetivo de examinar las relaciones entre las tomas de posición y argumentos, por un lado, y la posición social de los individuos entrevistados, que participan en el debate público sobre este tema, a pesar de actuar en diferentes campos del mundo social. Construido de esta forma, el objeto de la investigación se introduce en el ámbito de la sociología de inspiración bourdieusiana y, en particular, en su teorización sobre los campos sociales. Para llevar a cabo la investigación, entre finales del 2013 e inicios del 2014 se entrevistó, a partir de un guion semiestructurado, a 103 individuos, de todas las regiones de Brasil, que generalmente participan en el debate educacional (academia, sociedad civil, educación básica, sindicatos, gestión pública). Este análisis permitió construir las tomas de posición, relacionadas con algunas de las posiciones sociales de los individuos, especialmente con su posición en su campo y con relación a las esferas de decisión política.

Palabras clave: Currículo. Base Nacional Común Curricular. Política educacional. 
BERNSTEIN, Basil. Class, code and control: the structuring of pedagogic discourse. Londres: Routledge \& Kegan Paul, 1990.

BOURDIEU, Pierre. Algumas propriedades dos campos. In: Questões de sociologia. Rio de Janeiro: Marco Zero, 1983. p. 89-94. . Raisons pratiques. Paris: Seuil, 1994.

Décrire et prescrire: Note sur les conditions de possibilité et les limites de l'efficacité politique. Actes de la recherche en sciences sociales, n. 38, p. 69-73, Mai 1981.

BOURDIEU, Pierre; WACQUANT, Loïc. An Invitation to Reflexive Sociology. Cambridge, Uk: Polity Press, 1992.

BRASIL. Lei n. 13.005, de 25 de junho de 2014. Aprova o Plano Nacional de Educação - PNE e dá outras providências. Brasília, 2014.

DUBET, François. Os limites da igualdade de oportunidades. Cadernos Cenpec, São Paulo, v. 2, n. 2, p. 171-179, dez. 2012. Disponível em: 〈http://cadernos. cenpec.org.br/cadernos/index.php/cadernos/article/view/187/215〉. Acesso em: 16 abr. 2018.

ECO, Umberto. Lector in Fabula. 2 ed. São Paulo: Perspectiva, 1986. 222 p. (Coleção Estudos, 89).

\section{SOBRE OS AUTORES}

Antônio Augusto Gomes Batista é doutor em Educação pela Universidade Federal de Minas Gerais (UFMG). Atua como coordenador da Coordenação de Desenvolvimento de Pesquisas do Centro de Estudos e Pesquisas em Educação, Cultura e Ação Comunitária (Cenpec).

E-mail: antonio.batista@cenpec.org.br

Rosário Silvana Genta Lugli é doutora em Educação pela Universidade de São Paulo (2002). Atualmente é docente da Universidade Federal de São Paulo (Unifesp).

E-mail: genta.lugli@unifesp.br; gentalugli@gmail.com 
Vanda Mendes Ribeiro é doutora em Educação pela Universidade de São Paulo e professora do programa de pós-graduação em Educação da Universidade Cidade de São Paulo (Unicid). Foi colaboradora da Coordenação de Desenvolvimento de Pesquisas do Cenpec entre 2013 e 2016.

E-mail:vandaribeiro2@gmail.com

Recebido em: agosto de 2017

Aprovado em: outubro de 2017 